\section{Effects of Carbon Source and Explant Type on Somatic Embryogenesis of Four Cacao Genotypes}

\author{
Abdoulaye Traore ${ }^{1}$ \\ School of Forest Resources, The Pennsylvania State University, University \\ Park, PA 16802
}

Mark J. Guiltinan

Department of Horticulture, The Pennsylvania State University, 422 Life Sciences Building, University Park, PA 16802-4200

Additional index words. petal, staminode, tissue culture

\begin{abstract}
The effects of five carbon sources (glucose, fructose, maltose, sorbitol, and sucrose) and two explant types (petals and staminodes) on cacao somatic embryogenesis was studied. No growth was observed on both types of explants cultured on sorbitol containing media and slow growth was obtained on media supplemented with maltose. Depending on the genotype, the percentage of explants producing one or more embryos ranged from $6 \%$ to $99 \%, 18 \%$ to $98 \%$, and $3 \%$ to $82 \%$ on media containing glucose, fructose and sucrose respectively. Explants cultured continuously on maltose or sorbitol-containing media failed to produce embryos. Staminode explants produced 3 to 10 times more somatic embryos than petals. A strong genotypic effect on somatic embryogenesis was observed. Staminode explants of the Forastero clones Laranja and PSUSca 6 produced 2 to 30 times more somatic embryos than the Trinitarios UF 613 and ICS 16. During embryo maturation and conversion, no significant differences were observed among glucose, fructose, maltose, or sucrose for embryo weight, total shoot and root production. However, we found that all plantlets produced on glucose had shoots with normal cacao leaves while the other carbon sources sometimes produced plantlets with cotyledon-like leaves.
\end{abstract}

In vitro propagation via somatic embryogenesis (SE) provides a means to produce large numbers of genetically identical and often pathogen-free plants. It can also be used to develop a genetic transformation system or to preserve germplasm via cryopreservation of somatic embryos. However, for these applications to be technically and economically feasible, it is essential to optimize the system variables to obtain high multiplication rates of quality embryos. In somatic embryogenesis protocols, a carbon source is required to provide the necessary energy and building blocks for the process. Sucrose and glucose have been widely employed; however other carbon sources have also been reported to be effective in supporting somatic embryogenesis in plants (Brown et al., 1995). For example, the effectiveness of maltose as a carbon source for somatic embryogenesis has been demonstrated in petunia (Raquin, 1983), alfalfa (Strickland

Received for publication 17 Oct. 2005. Accepted for publication 8 Jan. 2006. The authors thank Siela Maximova and John Carlson for critical reading of the manuscript, Zhijan Li for his helpful advice and Sharon Pishak for her technical support. We also extend our thanks to Yo Tiemoko (Director ofCNRA in Cote d'Ivoire), Sangare Abdourahamane (Director of the Central Biotechnology Laboratory at CNRA Cote d'Ivoire) and his technicians (Ale Emmanual, Toure Mah, Assovi Claude and Zran Emmanuel) for assisting with embryo maturation and conversion experiment. This research was supported by a grant to Mark Guiltinan from the American Cocoa Research Institute.

${ }^{1}$ Author to whom correspondence should be directed; axt14@psu.edu. et al., 1987), pine (Nagmani et al., 1993), pea (Loiseau et al., 1995), and apple (Daigny et al., 1996). In addition, maltose has been used to improve somatic embryo maturation in cacao (Lopez-Baez et al., 1993) and pine (Li et al., 1998). In maize, Swedlund and Locy (1993), indicated that sorbitol improved embryogenic calli production and plant regeneration. Fructose has been shown to induce large numbers of embryos in cucumber (Ladyman and Girard, 1991), and to promote more embryo production than sucrose, glucose or maltose when used at concentrations higher than $252 \mathrm{~mm}$ in pea (Loiseau et al., 1995).

In 1987, Elhag et al. reported a comparative study of sucrose, glucose and fructose effects on cacao somatic embryogenesis using calli induced from zygotic tissues. As a result of that study, the authors indicated that embryogenesis increased when sucrose was replaced by glucose or fructose; however, several somatic embryogenesis protocols using tissue from maternal origin were subsequently developed using sucrose (Alemanno et al., 1997; Figueira and Janick, 1993; Lopez-Baez et al., 1993; Sondahl et al., 1989). Li et al. (1998) reported a successful somatic embryogenesis protocol using maternal tissue (staminodes and petals), glucose and sucrose. Maximova et al. (2002, 2005) have further reported on this system and a related secondary embryogenesis procedure. Traore et al. (2003) also reported a cacao micropropagation system based on somatic embryo derived plantlet using glucose and sucrose. These studies described efficient production of cacao somatic embryos obtained from floral explants with sucrose and glucose, however the effects of various carbon sources on embryo production, maturation or conversion was not studied. In order to determine the relative efficacy of various carbon sources, and the most efficient explant type for cacao somatic embryogenesis, a comparative study of these parameters was performed. The objectives of this study were to identify the best combination of explant type and carbon source for efficient cacao somatic embryo production and to test the effects of various carbon sources on embryo maturation and conversion into plantlets.

\section{Material and Methods}

Plant materials. Staminodes and petal explants from immature flowers of four cacao genotypes (ICS 16, Laranja, PSUSca 6 and UF 613 ) were used. Cacao trees were grown in a greenhouse maintained at $70 \%$ to $80 \%$ relative humidity and 27 to $30{ }^{\circ} \mathrm{C}$ at the Pennsylvania State University, University Park, Pa. Flowers were surface sterilized for 20 min using $10 \%$ calcium hypochlorite solution, then dissected, and staminodes and petals cultured on various media in $100 \times 15 \mathrm{~mm}$ plastic petri dishes.

Media formulation. The DKW-based media protocol, according to Li et al. (1998), was used to test five different carbon sources: fructose, glucose, maltose, sorbitol and sucrose, each at a concentration of $100 \mathrm{mM}$. The other media components remained as reported by Li et al. (1998).

Somatic embryogenesis. Embryogenic callus was induced from staminode and petal explants by culturing them on primary callus growth (PCG) medium (Li et al., 1998) at 26 ${ }^{\circ} \mathrm{C}$ in the dark for $14 \mathrm{~d}$, after which they were transferred onto a secondary callus growth (SCG) medium (Li et al., 1998) and cultured at $26^{\circ} \mathrm{C}$ in the dark for $14 \mathrm{~d}$. Embryo development was initiated by a transfer of the explants from SCG medium to embryo development (ED) medium ( $\mathrm{Li}$ et al., 1998). In the first experiment, each of the media contained glucose, fructose, maltose, sorbitol or sucrose, and the explants were consecutively transferred to the next media with the respective carbon source. Data for explant growth were collected every 2 weeks by weighing a set of five randomly selected staminode or petal explants. In a second experiment, the different carbon sources were tested only on PCG medium, then the explants were transferred onto SCG containing glucose followed by a transfer to ED containing sucrose and glucose according to $\mathrm{Li}$ et al. (1998).

Two months after culture initiation, the percentage of embryogenic explants [(number of explants producing one or more embryos / total number of explant) $\times 100$ ] and the average number of embryos per responsive explant (number of embryos per number of explant producing one or more embryos) were recorded by counting the number of embryo-producing explants in each treatment and the number of embryos on each responsive explant. Each medium and carbon source combination was evaluated with four replicate plates containing 20 staminodes and 20 petals each per 
plate. The data were analyzed using analysis of variance (ANOVA) and Fisher's PLSD on the Statview software program (SAS Institute Inc, Cary, N.C.).

Somatic embryo maturation and conversion into plantlets. Somatic embryo maturation and conversion experiments were conducted at the CNRA (Centre National de Recherche Agronomic) tissue culture laboratory in Côte d'Ivoire (Ivory Coast), where somatic embryos were produced using flower explants from field grown cacao trees. The embryos from the Scavina 6 genotype were cultured according to Li et al. (1998) on ED media at a constant temperature of $26{ }^{\circ} \mathrm{C}$ in the dark until they reached the early torpedo stage. They were then transferred onto ED media containing fructose, glucose, maltose or sucrose. The embryos were cultured on each carbon source at $26^{\circ} \mathrm{C}$ in the dark until they reach $2 \mathrm{~cm}$ long or until they begin to show root or shoot formations.
At that point they were transferred onto primary embryo conversion media (PEC) media (Li et al., 1998) with their respective carbon source and cultured under a $16 \mathrm{~h}$ photoperiod and a light intensity of $160 \mu \mathrm{mol} \cdot \mathrm{m}^{-2} \cdot \mathrm{s}^{-1}$ at a constant temperature of $26^{\circ} \mathrm{C}$ for embryo conversion into plantlets. Each carbon source was studied with two experiments using 5 replicate plates containing 10 embryos each in the first experiment, and 4 replications plates in the second. Embryo weight was recorded every 2 weeks by transferring 5 embryos into a sterile empty petri dish and weighing them before a transfer onto fresh media. Percentage of shoot or root production was evaluated by scoring the number and type of shoot or root produced by the embryos in each Petri dish, 8 weeks after conversion initiation. The data were analyzed using analysis of variance (ANOVA) and Fisher's PLSD on the Statview software program (SAS Institute Inc, Cary, N.C.).

\section{Results}

Effect of carbon source on embryo production. To test the effectiveness of various carbon sources on explant growth, staminode and petal explants from PSUSca 6 cacao genotype were cultured on media containing $100 \mathrm{mM}$ of either fructose, glucose, maltose, sorbitol, or sucrose. One week after culture initiation, tissue swelling was observed on petal and staminode explants cultured on glucose, fructose or sucrose. Two weeks after culture initiation, visible callus formed on explants cultured in the presence of these three carbon sources but not on maltose or sorbitol (Fig. 1a). Embryo development was visible 2 weeks after explant transfer from SCG medium to ED medium (6 weeks after culture initiation). Similar to their effects on explant growth, fructose, glucose and sucrose supported embryo production with rates ranging from $6 \%$ to $99 \%, 18 \%$ to
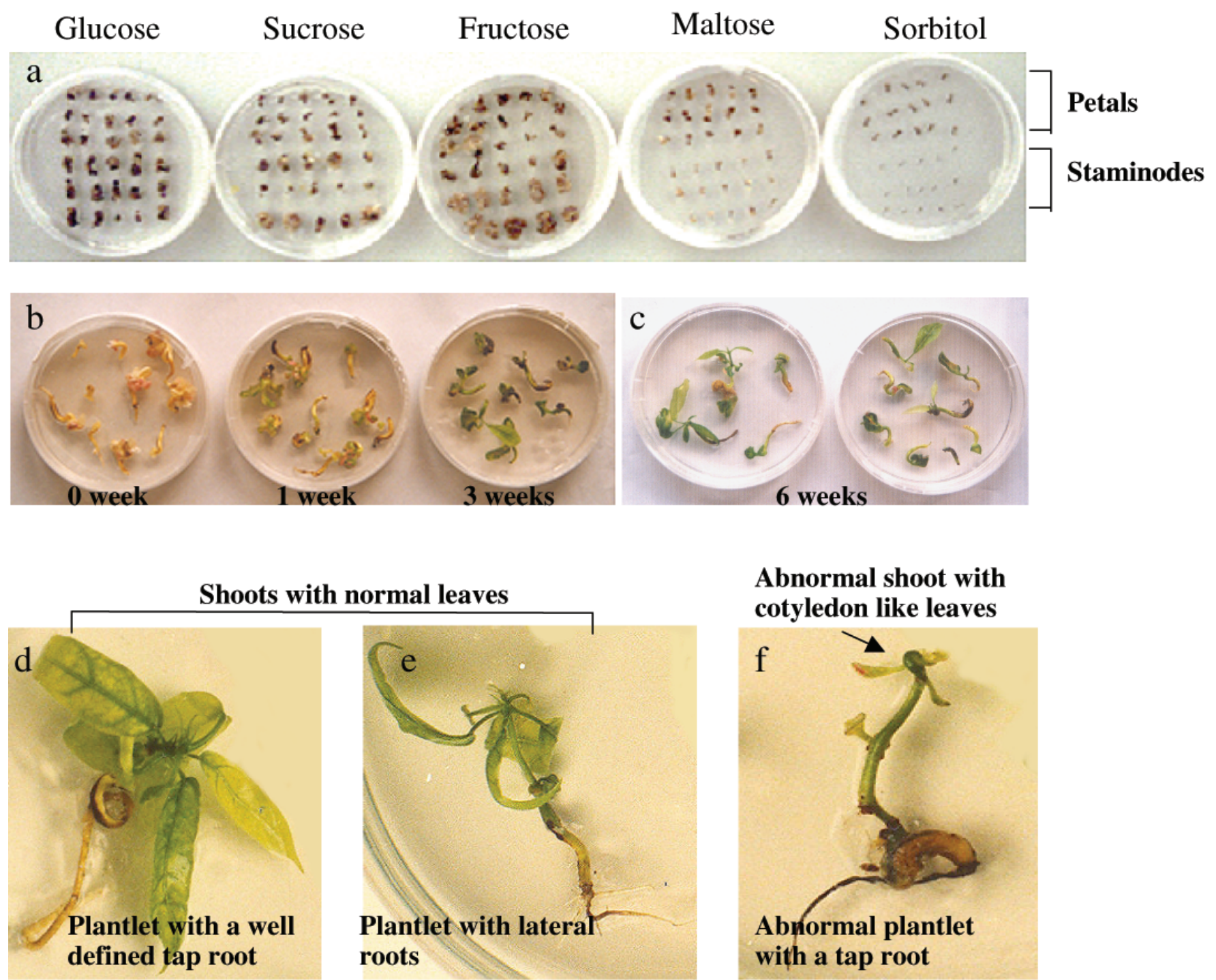

Fig. 1. Effect of various carbon sources on explant growth during cacao somatic embryogenesis initiation, somatic embryo maturation and conversion into plantlets. (a) Growth of cacao petal explants (top half of plates) and staminodes (bottom half of plates) in response to five different carbon sources as indicated at the top, 8 weeks after culture initiation. (b) Mature cacao somatic embryos on glucose containing media during conversion $(0,1$, and 3 weeks after a transfer from dark to light culture conditions). (c) Converted cacao somatic embryos on glucose containing media showing a growing shoot or root. (d) Cacao somatic embryos derived plantlet showing normal shoot and a well defined type roots. (e) Cacao somatic embryos derived plantlet showing normal shoot and lateral roots. (f) Cacao somatic embryos derived plantlet showing abnormal shoot (shoot with cotyledon-like leaves) and a tap root. 
$98 \%$ and $3 \%$ to $82 \%$ respectively, depending on the genotypes (Fig. 2a and 2b). Significant differences were observed for the percentage of embryogenic staminodes among all carbon sources $(p=0.001)$, except between fructose and sucrose $(p=0.591)$. Staminode and petal explants did not grow well on maltose or sorbitol containing media and did not produce any embryos (Figs. 1a and 2). When staminodes were cultured for 2 weeks to induce callus using PCG media containing glucose, fructose, maltose, or sucrose, then transferred onto SCG media containing glucose and ED media containing sucrose, according to $\mathrm{Li}$ et al. (1998), embryos were recovered (Fig. 3a and $b$ ). However embryo production rates were much lower for staminodes induced on maltose containing media ( $12 \%$ maximum) compared to a maximum of $78 \%, 97 \%$, and $99 \%$ on sucrose, glucose and fructose containing media, respectively (Fig. 3a). Sorbitol did not support embryo production. The average number of embryos per responsive staminode produced on glucose, fructose and sucrose containing media were not significantly dif- ferent ( $p=0.247$ ). On average, depending on the type of carbon source, 16.9 to 18 embryos per responsive staminode were produced from PSUSca 6 and 5.5 to 6.8 from Laranja (Fig. 2c). The only carbon source that supported embryo production from petal explants in all four genotypes was sucrose (Fig. 2b), with an average number of embryos per responsive petal ranging from 2.5 to 8 embryos.

Influence of explant type on the rate of embryoformation. To assess differences in explant responsiveness in the culture system described by Li et al. (1998), staminode and petal explants from immature flowers of ICS 16, Laranja, PSUSca 6 and UF 613 genotypes were cultured in the presence of various carbon sources. Staminode and petal explants increased in size during the first week after culture initiation. By the second week of culture, explant growth and expansion was more visible on staminodes than petals. After 8 weeks of culture, staminodes showed a higher growth response $(0.99 \mathrm{~g} / 5$ explants) than petals for which the growth response was $0.28 \mathrm{~g} / 5$ explants. In addition to increased fresh weight, a higher percentage of staminode explants produced embryos than did petal explants (Figs. 2 and 3). For example: $82 \%$ to $99 \%$ of staminodes from the PSUSca 6 genotype produced embryos compared to $12.5 \%$ to $33 \%$ from petals (Fig. $2 \mathrm{a}$ and $\mathrm{b}$ ). The same trend was also observed with the average number of embryos per responsive explant. Furthermore, the greater responsiveness of staminode explants was consistent across the four genotypes tested and the carbon sources that supported embryogenesis (Figs. 2 and 3 ). No explant by carbon source interaction was observed.

Influence of genotype on embryo production. The interaction of four different cacao genotypes (ICS 16, Laranja, PSUSca 6, and UF 613) with various carbon sources and explant types was evaluated. Except for ICS16 which did not produce embryos on fructose containing media, all other genotypes tested produced embryos when cultured on fructose, glucose or sucrose. A wide genotypic variation of embryogenesis rates was observed (Fig. 2a, b, c, and d), and was shown to be statistically significant between all genotypes $(p=0.001)$

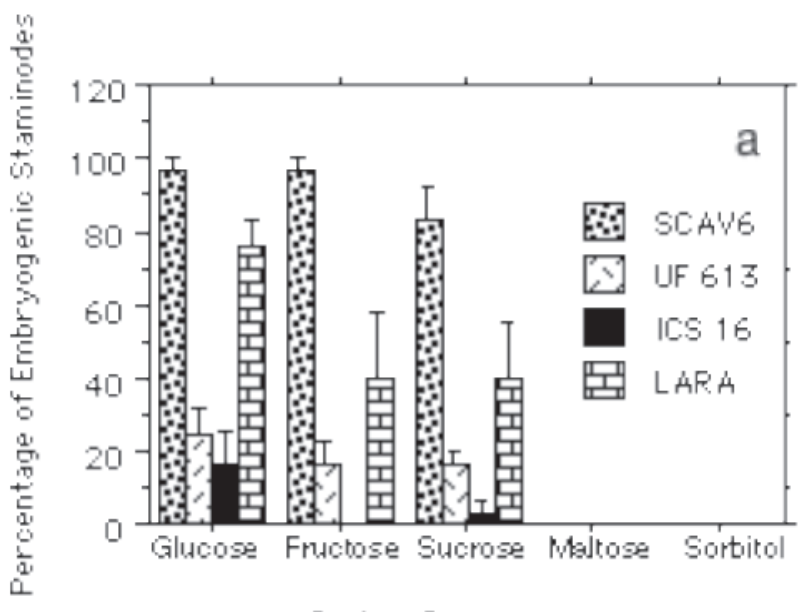

Carbon Source

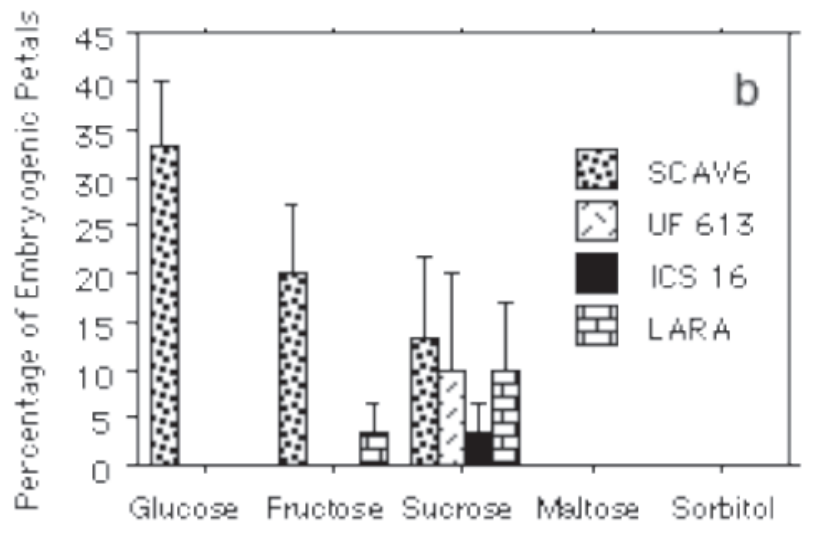

Carbon Source
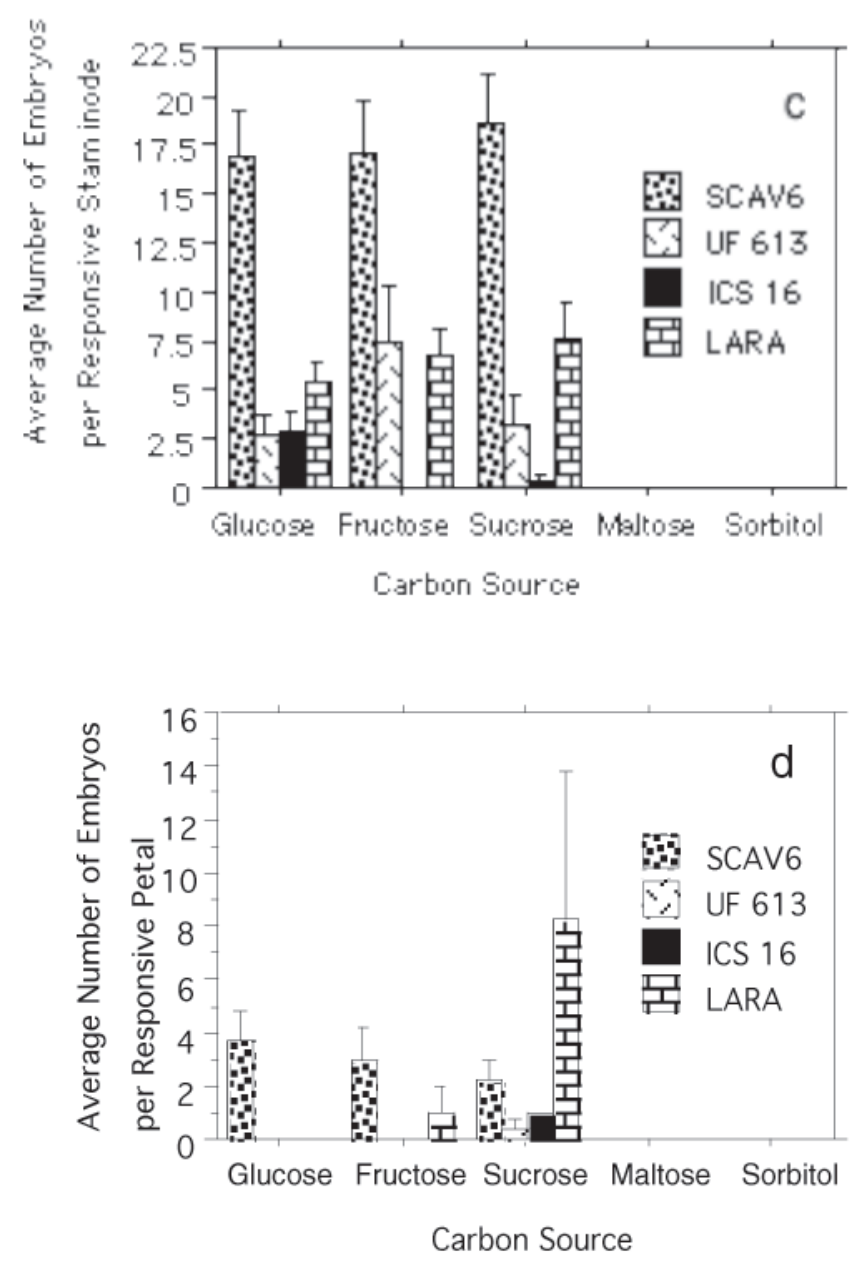

Fig. 2. Effect of carbon source and explant type on somatic embryo production in four cacao genotypes [ICS 16, Laranja, PSUSca 6 (SCAV6) and UF 613] . The explants were grown as described in Fig. 2 (Li et al., 1998b). Effect of carbon source on the frequency of somatic embryogenesis from (a) staminode explants. (b) petal explants. (c) average number of primary somatic embryos produced from each responsive staminode explant. (d) average number of primary somatic embryos produced from each responsive petal explant. The data were collected 2 months after culture initiation. Each treatment contained 80 explants from four replicate plates containing 20 explants each. Vertical lines represent the standard error of the means. Significant differences between carbon sources $(p<0.05)$ are indicated with different letters over the bars. 


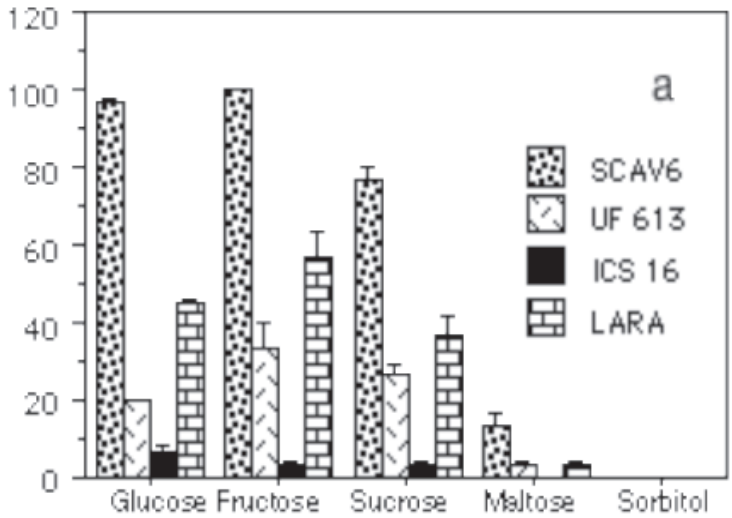

Carbon Source

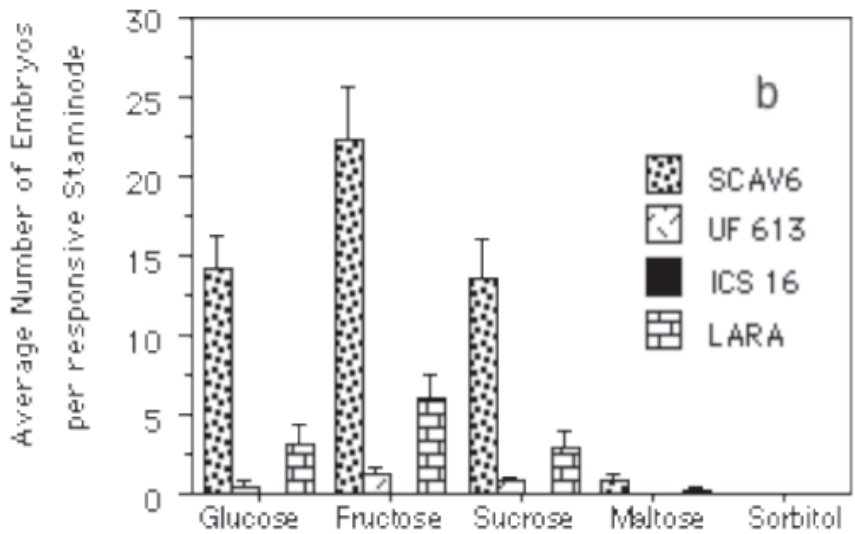

Carbon Source

Fig. 3. Effect of carbon source on somatic embryo induction from four cacao genotypes [ICS 16, Laranja, PSUSca 6 (SCAV6) and UF 613] using a DKW-based protocol (Li et al. 1998b). Effect of carbon source on (a) the frequency of somatic embryogenesis from staminode explants and (b) the average number of primary somatic embryos produced from each responsive staminode explant. Explants were cultured on the five different carbon source containing PCG media for 2 weeks then transferred onto SCG containing glucose for another 2 weeks before a transfer onto ED media containing sucrose according to Li et al. (1998b). The various carbon sources were tested only in PCG. The data were collected 2 months after culture initiation. Each treatment contained 80 explants from 4 replicate plates containing 20 explants each. Vertical lines represent the standard error of the means. Significant differences between carbon sources $(p<0.05)$ are indicated with different letters over the bars.

except UF613 and ICS16 $(p=0.096)$. The two Forastero genotypes (PSUSca 6 and Laranja) supported the highest embryogenesis rates ( $82 \%$ to $99 \%$ and $40 \%$ to $78 \%$ respectively). The Trinitarios (UF 613 and ICS 16) produced significantly lower embryogenesis rates $(18 \%$ to $22 \%$ and $1 \%$ to $18 \%$ respectively). The same trend was observed with petal explants cultured on sucrose containing media (Fig. 2b). Similarly, when staminodes were cultured on PCG with various carbon sources for 2 weeks before transfer to SCG then ED media according to the protocol by $\mathrm{Li}$ et al. (1998), PSUSca 6 and Laranja produced more embryos than did UF 613 and ICS 16 (Fig. 3). Genotypes with higher embryogenesis rates also produced more embryos per responsive staminodes in the following order: PSUScav 6 (17 to 18), Laranja (5 to 6), UF613 (2.5 to 7) and ICS16 (1 to 2.5). Though genotypic variation was observed for embryo production, no genotype by carbon source interaction was observed. A consistent trend of higher embryo production in glucose, fructose and sucrose than maltose and sorbitol was observed in all four genotypes tested.

Effect of carbon source on, maturation and conversion into plantlets. For embryo maturation and conversion studies, we used embryos from the genotype Scavina 6 from CNRA Côte d'Ivoire (Fig. 1b). All 4 carbon sources (fructose, glucose, maltose and sucrose) tested supported embryo maturation (Fig. 4). During the 6-week maturation period, the average weight of 5 embryos increased from (80 to 390, 450, 490, and $630 \mathrm{mg}$ for glucose, sucrose, maltose, and fructose respectively (Fig. 4), however, these were not statistically different $(p=0.06)$. For their conversion into plantlets after maturation, the embryos were transferred onto conversion media containing the respective carbon sources and grown under light conditions. One week after transfer from dark to light culturing condition, mature cacao somatic embryos began to turn green, and by week 3 the stem and cotyledons were completely green (Fig. 1b). Six weeks after their transfer under light, plantlets produced shoots with leaves and extended their radicle into a visible root (Fig. 1c). Total shoot production was low and not significantly different among carbon sources (Table 1). However, shoot quality was affected by carbon sources $(p=0.02)$. All shoots produced on glucose-containing media had normal leaves, while $20 \%, 40 \%$, and $66 \%$ of plantlets produced on fructose, sucrose and maltose respectively had abnormal

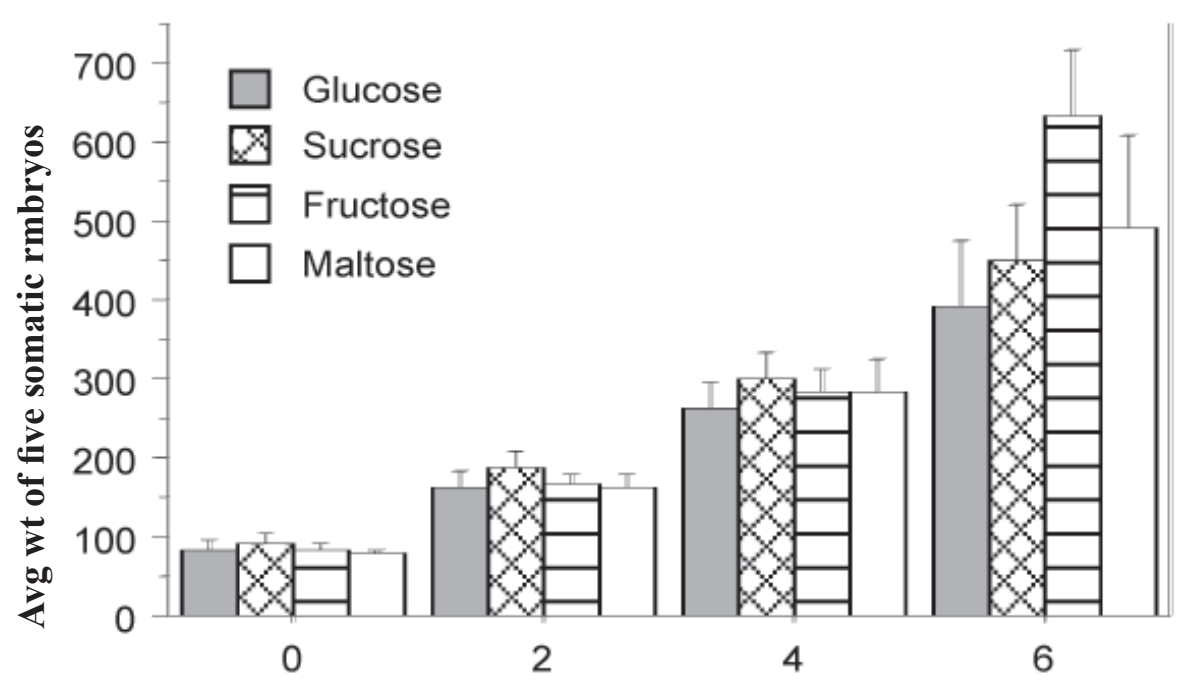

Time (weeks)

Fig. 4. Effect of four carbon sources on cacao somatic embryo maturation. Early torpedo stage of cacao somatic embryos from the West African Scavina 6 genotype were produced according to Li et al. (1998) and matured on ED media supplemented with glucose, sucrose, fructose, or maltose. The data were recorded every 2 weeks by weighing five somatic embryos. 
Table 1. Effect of carbon source on shoots formation during conversion of mature cacao somatic embryos.

\begin{tabular}{|c|c|c|c|c|c|c|c|c|}
\hline Carbon source & \multicolumn{2}{|c|}{ Glucose } & \multicolumn{2}{|c|}{ Fructose } & \multicolumn{2}{|c|}{ Sucrose } & \multicolumn{2}{|c|}{ Maltose } \\
\hline Percent of total shoot formation & \multicolumn{2}{|c|}{20} & \multicolumn{2}{|c|}{17} & \multicolumn{2}{|c|}{21} & \multicolumn{2}{|c|}{16} \\
\hline Percent of shoot type $\mathrm{z}^{z}$ & $\mathrm{~N}$ & $\mathrm{C}$ & $\mathrm{N}$ & $\mathrm{C}$ & $\mathrm{N}$ & $\mathrm{C}$ & $\mathrm{N}$ & $\mathrm{C}$ \\
\hline & 100 & 0 & 80 & 20 & 60 & 40 & 33 & 66 \\
\hline
\end{tabular}

${ }^{\mathrm{z}} \mathrm{N}=$ normal shoots, $\mathrm{C}=$ abnormal shoots with cotyledon like leaves.

Table 2. Effect of carbon source on root development during conversion of mature cacao somatic embryos.

\begin{tabular}{|c|c|c|c|c|c|c|c|c|}
\hline Carbon source & \multicolumn{2}{|c|}{ Glucose } & \multicolumn{2}{|c|}{ Fructose } & \multicolumn{2}{|c|}{ Sucrose } & \multicolumn{2}{|c|}{ Maltose } \\
\hline Percent of total root formation & \multicolumn{2}{|c|}{71} & \multicolumn{2}{|c|}{74} & \multicolumn{2}{|c|}{77} & \multicolumn{2}{|c|}{73} \\
\hline Percent of root type ${ }^{z}$ & $\mathrm{~T}$ & A & $\mathrm{T}$ & $\mathrm{A}$ & $\mathrm{T}$ & $\mathrm{A}$ & $\mathrm{T}$ & A \\
\hline & 55 & 45 & 70 & 30 & 75 & 25 & 60 & 40 \\
\hline
\end{tabular}

${ }^{{ }^{2} \mathrm{~T}}=$ clearly defined tap roots); $\mathrm{A}=$ adentitious or lateral roots.

of four cacao genotypes (ICS 16, Laranja, PSUSca 6 and UF 613), in combination with five different carbon sources (fructose, glucose, maltose, sorbitol and sucrose). The optimal embryo production was obtained with either glucose, fructose or sucrose. The ability of glucose, fructose and sucrose to support cacao tissue culture was also reported by Kononowics and Janick (1984) who indicated that glucose, in combination with sucrose or fructose, was better for cacao embryo growth than sucrose alone. Similarly, using calli from zygotic embryo tissue, Elhag et al. (1987) reported that glucose or fructose increased cacao somatic embryogenesis. Li et al. (1998) also reported that using glucose either alone or in combination with sucrose resulted in higher embryogenic responses from cacao tissue. In this report we showed that in addition to glucose and sucrose, the use of fructose in the media resulted in a high embryogenic response from cacao tissue. Though the difference was not statistically significant, embryos cultured on fructose during maturation also showed the highest weight after 6 weeks.

The influence of carbon sources on somatic embryogenesis has been reported in other plant species (Daigny et al., 1996; Parrott and Bailey, 1993; Strickland etal., 1987). Although sucrose is by far the most utilized carbon source for plant tissue culture, other sources such as glucose, fructose, lactose, mannitol, maltose, and sorbitol have also been used effectively for somatic embryogenesis in plants (Brown et al., 1995). Cuenca and Vieitez (2000) reported that for beech, glucose was more effective for shoot multiplication and growth than sucrose or fructose. While maltose was shown to be more effective than fructose, glucose or sucrose in apple somatic embryogenesis (Daigny et al., 1996), it was found to be toxic for cucumber somatic embryogenesis (Ladyman and Girard, 1992) and unsuitable for in vitro culture of immature pearl millet embryos (Oldach et al., 2001). Our study also indicated that maltose alone, did not support embryo production from cacao tissue, neither did sorbitol. In contrast, sorbitol has been reported to support the growth of maize embryogenic calli and to enhance its regenerative capacity (Swedlund and Locy, 1993). Within a species, tissue specific preference for carbon sources has been reported. For example, sorbitol was shown by Daigny et al. (1996) to be inefficient for apple somatic embryogenesis although it was quite useful for apple micropropagation (Pua and Chiang,
1983, 1985). Sorbitol is effectively translocated in apple and related species. Since it can be converted into glucose by sorbitol oxidase or into fructose by sorbitol dehydrogenase, its effectiveness on apple micropropagation and maize somatic embryogenesis was linked to the presence of high levels of these sorbitol metabolic enzymes. The ineffectiveness of sorbitol in cacao tissue culture might be due to a lack of these enzymes in cacao tissues but this has not been investigated.

A significant genotypic variation in the embryogenesis response was observed in this study. Cacao genotypes are divided into three major groups: 1) the Forastero group from the Amazon basin characterized by vigorous growth, better resistance to diseases and a strong chocolate flavor that requires fermentation to develop; 2) the Criollo group from central America and Mexico, characterized by its fine chocolate flavor, this group has less vigorous growth and is more susceptible to diseases, only few original genotypes remain in the wild or in cultivation; and 3) the Trinitario believed to be a hybrid between Forastero and Criollo (Wood and Lass, 1987). When cultured on media containing glucose, fructose or sucrose (carbon sources that can support cacao somatic embryogenesis), the Forastero genotypes PSUSca 6 and Laranja were more embryogenic than the Trinitario UF 613 and ICS 16. Genotypic effects on cacao embryogenesis efficiency have been previously reported (Lopez-Baez et al., 1993; Alemanno et al., 1996b; Li et al., 1998; Maximova et al., 2002). In their report on cacao somatic embryogenesis using flower parts, Lopez-Baez et al. (1993) obtained embryos from only the Forastero group. Similarly, Alemanno et al. (1996b) tested 25 genotypes from three cacao groups (Forastero, Trinitario and Criollo) and reported somatic embryogenesis from 5 genotypes, all from the Forastero group. In a previous report (Li et al., 1998), although embryogenesis was observed for all three cacao groups, embryogenesis rates were higher for Forasteros than Criollos, with Trinitarios expressing intermediate rates. Unlike previous reports (Li et al., 1998; Traore et al., 2000) where shoot production during cacao conversion was $>50 \%$, in this study, shoot production was $<20 \%$ during conversion. The low percentage in shoot production could be attributed to the genotypic and environmental differences between the trees used in this study and those used in the previous reports. In our study, somatic embryos used for the conversion were produced in the Côte d'Ivoire (Ivory Coast) using flower explants from trees living in field conditions, while conversion rate reported by $\mathrm{Li}$ et al. (1998) and Traore et al. (2000) were from somatic embryos produced using trees grown in a greenhouse with highly uniform growth conditions. The influence of genotype on somatic embryogenesis is also well established in other plant species (Merkle et al., 1995).

While flower parts such as anthers, ovules and ovaries are frequently used as explants for somatic embryogenesis in many plant species, other flower parts such as petals and stamens (in particular anther filaments or staminodes) are only rarely used. Flower parts other than ovules, ovaries and anthers have been shown to be responsive for embryogenesis in Iris species (Jéhan et al., 1994), in Coco nucefera (Verdeil et al., 1995), in Cavendish banana (Navarro et al., 1997), in Lilium logiflorum (Tribulato et al., 1997), and in Citrus (Carimi et al., 1999). In cacao, although somatic embryos have been produced from nucellar tissue (Figueira and Janick, 1993) and leaf explants (Litz, 1986), petal, anther filament and staminode explants were more successful maternal tissue (LopezBaez et al., 1993; Alemanno et al., 1996a, 1996b; Li etal., 1998; Sondahl etal., 1989). The present study revealed the higher responsiveness of staminode explant compared to petal explants for cacao somatic embryogenesis in the genotypes tested.

Our study showed that during conversion of embryos into plantlets, root development and total shoot production was not significantly affected by carbon source, but shoot quality was. Embryos cultured on glucose containing media produced normal shoots while other carbon sources sometimes produced plantlets with cotyledon-like leaves. As embryos begin the conversion into plantlets they undergo the equivalent of germination in seed and their energy requirement increases. During germination, shoot and root meristems become metabolically active and require a source of energy for the production of new tissue. Cacao seeds have no dormancy. When mature they germinate or die. A similar phenomenon could be expected for somatic embryos. In this work, the production of organs similar to cotyledon on media with no glucose is an indication that some of these embryos, though triggered to undergo conversion (with the production of a shoot), are also continuing to build up an energy reserve that can be used for the rest of 
conversion. At each stage, it is important that the most appropriate carbon source is identified to avoid the production of plantlets with abnormalities, and to increase the efficiency of clonal production so it can be used at a large scale.

\section{Literature Cited}

Alemano, L., M. Berthouly, and N. MichauxFerrière. 1996. Embryogenèse somatique du cacaoyer à partir de pièce florales. Plant Rech. Dev. 3:225-233.

Brown, D.C.W., K.I. Finstad, and E.M. Watson. 1995. Somatic embryogenesis in herbaceous dicots, p. 155-203. In: T.A. Thorpe (ed.). In vitro embryogenesis in plants. Kluwer Academic Publ., Dordrecht, The Netherlands.

Carimi, F., F. De Pasquale, and F.G. Crescimanno. 1999. Somatic embryogenesis and plant regeneration from pistil thin layers of Citrus. Plant Cell Rpt.18:935-940

Cuenca, B. and M. Vieitez. 2000. Influence of carbon source on shoot multiplication and adventitious bud regeneration in in vitro beech cultures. Plant Growth Regulat. 32:1-12

Daigny, G., H. Paul, R.S. Sangwan, and B.S. Sangwan-Norreel. 1996. Factors influencing secondary somatic embryogenesis in Malus $\times$ domestica Borkh. (cv `Gloster 69'). Plant Cell Rpt. 16:153-157

Elhag, H.M., A. Whipkey, and J. Janick. 1987. Induction of somatic embryogenesis from callus in Theobroma cacao L. in response to carbon source and concentration. Revista Theobroma 17(3):153-162

Figueira, A. and J. Janick. 1993. Development of nucellar somatic embryos of Theobroma cacao L. Acta Hort. 336:213-236

Jéhan, H., D. Courtois, D. Ehret, K. Lerch, and V. Petiard. 1994. Plant regeneration of Iris pallida Lam. and Iris germanica L. via somatic embryogenesis from leaves, apices and young flowers. Plant Cell Rpt. 13:671-675

Kononowicz,A.K. and J. Janick. 1984. The influence of carbon source on the growth and development of asexual embryos of Theobroma cacao L. Physiol. Plant. 61:155-162

Ladyman, J.A.R. and B. Girard. 1992. Cucumber somatic development on various gelling agents and carbohydrates sources. HortScience 27:164-165

Li, X.Y., F.H. Huang, B.J. Murphy, and E.E. Gbur, Jr. 1998a. Polyethylene glycol and maltose enhance embryo maturation in loblolly pine (Pinus taeda L.). In vitro Cell. Dev. Biol. Plant 34:22-26

Li, Z.; A. Traore, S. Maximova, and M.J. Guiltinan. 1998b. Somatic embryogenesis and plant regeneration from floral explant of cacao (Theobroma cacao L.) using thidiazuron. In vitro Cell Dev Biol Plant 34:293-299

Litz, R.E. 1986. Tissue culture studies with Theobroma cacao L., p. 111-120. In: P.S. Dimick(ed.). Cacao biotechnology symposium proceedings. Pa. State Univ. Press, University Park.

Loiseau, J., C. Marche, and Y. Le Deunff. 1995. Effects of auxins, cytokinins, carbohydrates and amino acids on somatic embryogenesis induction from shoot apices of pea. Plant Cell. Tiss. Organ Cult. 41:267-275

Lopez-Baez, O., H. Bollon, and A. Eskes. 1993.Embryogenèse somatique de cacaoyer Theobroma cacao L. à partir de pièces florales. C.R. Acad. Sci. Paris 316:579-584

Maximova, S.N., L. Alemano, A. Young, A. Traore, N. Ferrier, and M.J. Guiltinan. 2002. Genotypic variability, efficiency and cellular origin of primary and secondary somatic embryogenesis of Theobroma cacao L., The chocolate tree. In vitro Cell. Dev. Biol. Plant 38:252-259

Maximova, S.N., A. Young, S. Pishak, C. Miller, A. Traore, and M.J. Guiltinan. 2005. Integrated system for propagation of Theobroma cacao L. In: S. Jain, G. Mohan, and K. Pramod(eds.). Forestry sciences. vol. 77. Protocol for somatic embryogenesis in woody plants. Springer, Dordrecht, The Netherlands

Merkle, S.A., W.A. Parrott, and B.S. Flinn. 1995 Morphogenic aspects of somatic embryogenesis, p. 155-203. In: T.A. Thorpe (ed.). In vitro embryogenesis in plants. Kluwer Academic Publ., Dordrecht, The Netherlands,

Nagmani, R., A.M. Diner, and G.C. Sharma. 1993. Somatic embryogenesis in longleaf pine (Pinus palustris). Can. J. For. Res. 23:873-876

Navarro, C., R.M. Escobedo, and A. Mayo. 1997. In vitro plant regeneration from embryogenic cultures of a diploid and a triploid, Cavendish banana. Plant Cell, Tiss. Organ Cult. 51:17-25

Oldach, K.H., A. Morgenstern, S. Rother, M. Girgi, M. O'Kennedy, and H. Lörz, 2001. Efficient in vitro plant regeneration from immature zygotic embryos of pearl millet (Pennisetum glaucum L. R.Br.) and Sorghum bicolor L. Moench. Plant Cell Rpt. 20:416-421

Parrott, W.A. and M.A. Bailey. Characterization of recurrent somatic embryogenesis of alfalfa on auxin-free medium. 1993. Plant Cell. Tiss. Organ Cult. 32:69-76

Pua, E-C. and C. Chong. 1983. Requirement for sorbitol (D-glucitol) as carbon source for in vitro propagation of Malus robusta No. 5. Can. J. Bot. 62:1545-1549

Pua, E-C., and C. Chong. 1985. Regulation of in vitro shoot and root regeneration in 'Macspur' apple by sorbitol (D-glucitol) and related carbon sources. J. Amer. Soc. Hort. Sci. 110:705-709

Raquin, C. 1983. Utilization of different sugars as carbon source for in vitro anther culture of Petunia. Z.Pflanzenphysiol 111:453-457

Sondahl, M.R., S. Liu, and C. Bellato. 1993. Cacao somatic embryogenesis. Acta Hort. 336:245-248

Strickland, S.G., J.W. Nichol, C.M. McCall, and A.D. Stuart. 1987. Effect of carbohydrate source on alfalfa somatic embryogenesis. Plant Sci. 48:113-121

Swedlund, B. and R.D. Locy. 1993. Sorbitol as the primary carbon source for the growth of embryogenic callus of maize. Plant Physiol. 103:1339-1346

Traore, A. 2000. Somatic embryogenesis, embryo conversion, micropropagation and factors affecting genetic transformation of Theobroma cacao L. PhD thesis. Pa. State Univ.,University Park.

Traore, A., S.N. Maximova, and M.J. Guiltinan. 2003. Micropropagation of Theobroma cacao L. using somatic embryo-derived plants. In vitro Cell. Dev. Biol. Plant 39:332-337

Tribulato, A.; P.C. Remotti, H.J.M. Löffler, and J.M van Tuyl. 1997. Somatic embryogenesis and plant regeneration in Lilium longiflorum Thumb. Plant Cell Rpt. 17:113-118

Verdeil, J.L. and J. Buffrad-Morel, 1995. Somatic embryogenesis in coconut (Cocos nucifera L.). In:Y.P.S. Baja (ed.). Biotechnology in agriculture and forestry. vol. 30. Somatic embryogenesis and synthetic seeds I. Sringer-Verlag, Berlin, p. 299-317

Wood, G. A. R., and R. A. Lass. 1987. Cocoa. 4th ed. Longman Scientific and Technical-John Wiley \& Sons, New York. 